\title{
Moral competency: meta-competence of nursing care
}

\author{
Niloofar Zafarnia ${ }^{1}$, Abbas Abbaszadeh ${ }^{2}$, Fariba Borhani ${ }^{3}$, Abbas Ebadi $^{4}$, Nouzar Nakhaee ${ }^{5}$
}

${ }^{1}$ Ph.D in Nursing Education, M.Sc. in Nursing Education, a) Bam University of Medical Sciences, Bam, Iran b.) Nursing Research Center, Razi Faculty of Nursing and Midwifery, Kerman University of Medical Sciences, Kerman, Iran

${ }^{2}$ Ph.D. in Nursing Education, Professor, Department of Medical Surgical Nursing, School of Nursing and Midwifery, Shahid Beheshti University of Medical Sciences, Tehran, Iran

${ }^{3}$ Ph.D. in Nursing Education, Associate Professor, Medical Ethics and Law Research Center, School of Nursing and Midwifery, Shahid Beheshti University of Medical Sciences, Tehran, Iran

${ }^{4}$ Ph.D. in Nursing Education, Associate Professor of Behavioral Sciences Research Center, Nursing Faculty, Baqiyatallah University of Medical Sciences, Tehran, Iran

${ }^{5}$ Ph.D. in Community Medicine, Professor of Community Medicine, Neuroscience Research Center, Institute of Neuropharmacology, Kerman University of Medical Sciences, Kerman, Iran

\section{Type of article: Original}

\begin{abstract}
Introduction: To follow the progress of technology and increasing domain of nurses' duties, ethical challenges can be observed more than ever. Therefore, the growing and dynamic system of nursing requires nurses with professional and ethical competence who can provide optimal care. The aim of the present study was to define and explain dimensions of moral competency among the clinical nurses of Iran.

Methods: This qualitative content analysis study was carried out in the years 2014 and 2015 in Iran. Data were collected through in-depth semistructured interviews and field notes. The resulting data were analyzed by Graneheim and Lundman's method of conventional content analysis. The participants were 12 clinical nurses who were selected using purposive convenient sampling and continued interviews until data saturation.

Results: Themes obtained in the present study were posited in three main categories of "moral character," with subcategories of altruism, search for meaning, be pioneering, perfectionism, self-control, honesty, and forgiveness; "moral care" with subcategories of dignified care, safe care, fair care, and holistic care; and "moral decision-making" with subcategories of moral sensitivity, moral thinking, moral reasoning, and moral courage.

Conclusions: Findings of the present study suggest that nurses' moral competency is an adorable character with a wide range that includes moral virtues and character, moral decision-making, and ultimately providing moral care; therefore, moral competency is a meta-competence in the field of nursing. Because there are many competencies in different fields.
\end{abstract}

Keywords: Moral competency, Meta-competence, Moral authority, Moral care, Decision making; Nurse

\section{Introduction}

According to numerous improvements and increase of awareness and society's expectations in today's world of health care systems, health care nurses, who number the most in a health care team, are expected to be competent in all aspects of their profession (1-4). Thus, it is recommended that nurses plan and implement their care and behavior based on competency. Due to advances in technology and science, nurses are expected to increase their knowledge in accordance with the collective awareness and science (5). Given the expanding role of nurses in public health, facing the moral challenges and necessity of taking ethical decisions (6), those nurses will be more successful in

\section{Corresponding author:}

Professor Dr. Abbas Abbaszadeh, Department of Medical Surgical Nursing, School of Nursing and Midwifery, Shahid Beheshti University of Medical Sciences, Tehran, Iran.

Tel: +982188202520, Fax: +982188202521, Email: aabaszadeh@hotmail.com

Received: June 30, 2016, Accepted: September 02, 2016, Published: June 2017

iThenticate screening: August 08, 2016, English editing: February 11, 2017, Quality control: March 10, 2017

(C) 2017 The Authors. This is an open access article under the terms of the Creative Commons Attribution-NonCommercialNoDerivs License, which permits use and distribution in any medium, provided the original work is properly cited, the use is non-commercial and no modifications or adaptations are made. 
their profession and patient care when taking part in decision-making that requires moral challenges with professional skills and moral authority. Thus, the dynamic and growing system of nursing requires nurses with professional and ethical competence who can provide optimal care (7). Competence in general means a person holding a professional capacity and capability in establishing a career and providing excellent quality results. In other words, knowledge and skills used in practice is called "competence" (8) Competence in nursing includes clinical, morals, and public competence $(9,10)$. Therefore, regarding moral competency in the field of health and care, especially in the nursing profession, is essential because the quality of patient care depends on staff morality. Investigation of the concept of moral competency is raised in the international level. European Commission (under the Europe jurisdiction) described moral competency as the meta-competency, an integral part of the knowledge and skills, and competence and as an essential component for development of accountability and independence (11). The World Health Organization also paid special attention to moral competency and referred to that in the competence global model under the title of "basic competencies" (12). But the question remains: "Is that what moral competency really means?" How can we make judgments about it when we disagree on moral competency as an essential part of responsibility and safe nursing care (13)? Many studies have been conducted in Iran and other countries in the past decade on nursing ethics, but all have dealt with one or more dimensions of nurses' moral competency, including moral distress among nurses (14), maintaining dignity of patients (15-17), and showing moral judgment or moral courage (18). Except for Gallagher, other scholars have focused on defining values and attitudes and personality traits such as kindness, sobriety, honesty, respect $(8,19)$. Although these traits are important components of moral competency, knowledge, skills, and capability in work are integral in moral competency $(20,21)$. Accordingly, no comprehensive definition of the notion that covers all of its aspects has yet been presented (20). Nurses make great efforts to provide patients with the best care, but others inside and outside the health system always comment on their morality. Are there good measures at hand for these judgments (22)? Which nurse has more moral competency and which has less? It is a difficult question that can be answered only in the case of having a clear and precise definition of qualified nursing ethics, describing its aspects, and then having the right tools. Therefore, the present study aimed to explore and define dimensions of moral competency of nurses. Taking into consideration the fact that morality is teachable, changes can be proposed and applied in nursing curriculum to train nurses to demonstrate better moral competency, which can be the basis for future studies and investigation of nursing moral competency and its relationship to other concepts related to nursing. Ultimately, all be applied to serve the patients and increase the quality of patient care.

\section{Material and Methods}

\subsection{Research design}

The present study has been carried out in 2014 and 2105 in the field of providing health care and medical education of Iran among the community nurses working in the Shafa, Afzalipour, and Bahonar hospitals of Kerman; Pasteur hospitals of Bam and Namazian, and Shiraz hospitals and Alzahra of Esfahan. This qualitative study was conducted using conventional content analysis, which is part of a broader research. Conventional content analysis is one of the methods of qualitative research and data analysis. Content analysis helps researchers to uncover the hidden and underlying layers of the phenomena related to research subject (23). The aim of this method is vast, compressing and describing of concepts and classes of a phenomenon. Sampling, which started in 2014, was carried out in purposive form and continued until data saturation.

\subsection{Data collection and interviews}

Semistructured interviews and notes were taken in the field. Inclusion criteria were nurses working in each section and clinics for at least one year. Participants in the study included 12 nurses - nine female and three male; nine of whom had a bachelor's degree and three had a Master of Science degree. Three of the participants were employed in Isfahan, one in Shiraz, one in Tehran, three in Kerman, and four in Bam. Work experience was on average nine years and six months. Participant's mean age was 33.5 years (Table 1). Interviews lasted on average for 45 minutes each. Interviews started with some predetermined questions such as "What are the qualifications of your best colleague?" and "What qualifications do you consider a nurse requires to provide moral care?" and other questions were raised during the interview. Interviews were recorded, written in words, transcripts read several times, and then encoded. The first encoded interview was listened by the research collaborators, and the encoding trend was reformed and continued. The Lincoln and Guba criteria were as follows: Data were repeatedly read in order to understand what was achieved and then analyzed using the constant comparative methods and inductive content analysis. To validate data from long-term involvement, the manuscripts and recordings, the supervisory overview and continuous comparison of data were used (24). Dependency indicated the stability and reliability of the data. For this end, member check was used in the form of using partners' complementary ideas and review of manuscripts by 
the participants. After presenting the reports, manuscripts, and notes to three nursing faculties and obtaining unit results, confirmation of the findings became clear. The research transferability was provided through rich descriptions of data (25).

Table 1. Participants characteristic

\begin{tabular}{|l|l|l|l|l|}
\hline ID & City & Study level & Job experience (years) & Age (years) \\
\hline 1 & Bam & BS & 12 & 36 \\
\hline 2 & Bam & BS & 6 & 28 \\
\hline 3 & Kerman & MS & 13 & 37 \\
\hline 4 & Esfahan & BS & 17 & 43 \\
\hline 5 & Esfahan & BS & 17 & 43 \\
\hline 6 & Bam & BS & 7 & 30 \\
\hline 7 & Esfahan & BS & 2 & 26 \\
\hline 8 & Kerman & BS & 6 & 27 \\
\hline 9 & Tehran & MS & 10 & 35 \\
\hline 10 & Shiraz & MS & 11 & 36 \\
\hline 11 & Bam & BS & 20 & 50 \\
\hline 12 & Bam & BS & 6 & 28 \\
\hline
\end{tabular}

\subsection{Ethical considerations}

In the current study, the principles of confidentiality and informed consent for interviews and recordings were observed and the right to withdraw from the study at any time of the participant will was told to them. The study was confirmed by the Ethics Committee of Kerman University of Medical Sciences with ethical code "487/93/KA."

\section{Results}

Themes obtained from the participants' answers to the research questions were classified in three main categories: 1) "moral character" with subcategories of altruism, search for meaning, be pioneering, perfectionism, self-control, honesty, forgiveness; 2) "moral decision" with subcategories of moral sensitivity, moral thinking, moral reasoning, and moral courage; and 3) "moral care" with subcategories of dignified care, safe care, fair care, and holistic care (Table 2).

Table 2. Main theme, main categories and Subcategories

\begin{tabular}{|c|c|c|}
\hline Main Theme & Main category & Subcategory \\
\hline \multirow[t]{15}{*}{ Moral competency } & \multirow[t]{7}{*}{ Moral character } & Altruism \\
\hline & & Search for meaning \\
\hline & & Be pioneering \\
\hline & & Perfectionism \\
\hline & & Self-control \\
\hline & & Honesty \\
\hline & & Forgiveness \\
\hline & \multirow[t]{4}{*}{ Moral decision-making } & Moral sensitivity \\
\hline & & Moral thinking \\
\hline & & Moral reasoning \\
\hline & & Moral courage \\
\hline & \multirow[t]{4}{*}{ Moral care } & Dignified care \\
\hline & & Safe care \\
\hline & & Fair care \\
\hline & & Holistic care \\
\hline
\end{tabular}

\subsection{Moral character}

Moral character is the first theme that emerged from the interviews. The integration of features such as altruism, search for meaning, pioneering, perfectionism, self-control, honesty, and forgiveness forms a moral character. Characteristic traits are qualities that the person acquires based on culture, religion, genetics, etc. during the time and enables them to manage their hard positions, know the limitations, and build a relationship based on respect and trust. 


\subsubsection{Altruism}

Altruism is the first and largest subclass of moral character. Most participants consider altruism as necessary characteristics for nurses, which includes attribute of empathy, philanthropy, benevolence, sincerity, forgetting personal problems when working, feelings of passion in work and care, and desire to service. Participant no. 6 said: "I love all people, especially the suffering."

\subsubsection{Search for meaning}

Search for meaning another subcategory of the present study, which has implications of moral health and expecting spiritual reward. Nurses' motivation of care in the present study was not a material incentive but to follow their existence sense. Participant no. 10 said, "I was working with the patient, suddenly I found that it was eight o'clock in the morning and that was late for my prayer. We worked intensely from $9 \mathrm{pm}$, and I had no bad feeling about my prayer being late. I think that was nothing less than a spiritual worship, service to patients creates a good sense of being useful in me, which was more than a sense of responsibility. When I got home I was quite satisfied."

\subsubsection{Be pioneering}

Be pioneering is the next subcategory and includes themes of leading power and following others' moral patterns. Be pioneering means being prepared to start before others and taking action, and it intentionally or unintentionally makes you become a role model and leader because it is not found in all, and others require someone starts to follow him. Participant no. 8 stated: "When a new patient was got to emergency, he was the first to get to the patient. When a new scientific routine was raised in credo, he accepted that easier than the rest and led us to accept the changes."

\subsubsection{Self-control}

Self-controlling is another subcategory that, according to participants, including criticism, self-assessment, patience, restraint, and calm. This feature has caused the nurses to patiently attend others' assessment and evaluation of their actions and provide their own growth through assessing their actions and intentions. For example, participant no. 4 said: "You should monitor yourself and think of your actions, if someone finds your faults, you should accept criticism."

\subsubsection{Perfectionism}

Perfectionism or demand for the best is another subcategory of this study and is a combination of perfectionism, magnanimity, and positive thinking. Perfection is achieved when a person integrates all the virtues and links them to principles and acts accordingly. Participant no. 3 stated: "I always tells to the students or staff who just come into our port that we just not come to dressing or medicine, but despite of giving great nursing care we should think in the fact that our profession going to be the way to achieve higher growth rates. This is my philosophy of care. We give best care to deserve the best."

\subsubsection{Honesty}

Honesty is another subcategory of moral characteristic and is a combination of truthful and respect for another's trust. Honesty is not only truthful but also is valuable to an individual's need to know the truth. Participant no. 4 participant stated: "I was so glad when my colleague had confessed his error. I had good feeling that she had not lied. Because not only was benefit for patients but also she respect to trust that I had to her." Participant no. 10 said: "The patient wanted to go to the operating room. He was so scared about the surgery. Nurses didn't tell her the truth about surgery. We should not to give patients false hope."

\subsubsection{Forgiveness}

Another concept noted by participants is thoughtful forgiveness, which includes the subcategories of forgiveness and remission. Forgiveness is the characteristic of the person's transformation from negative to positive in response to his or her own error or wrongdoers and is a mechanism through which people can experience hope and positive emotions and relieve negative emotions. Participant no. 5 stated: "I blamed myself for a long time for the mistakes that really were not intentional. But I am human. I did not feel good until one day I told myself it is enough. Do not reprimand yourself; do not tell God repent, I forgive you? Well, you too forgive yourself."

\subsection{Moral decision-making}

The next theme is moral decision-making, which is based on the participants' statements including subcategories of moral sensitivity, moral thinking, moral reasoning, and moral courage. Moral decision making is based on thinking in which there are certain moral principles and carried out through moral reasoning and focused on goal, intentions, and the decisions results. Thus, the need to courage is implicit within it.

\subsubsection{Moral sensitivity}

Subcategories of moral sensitivity include themes of commitment to the values and conscience. Moral sensitivity helps people in recognizing moral conflict, understanding and describing the individuals' vulnerability and enables him to find other insights about the outcome of the moral decision-making. Participant no. 7 said, "I cannot see the 
patient is suffering with your negligence." Participant no. 2 said, "Think based on the principles that are valuable for yourself and don't leave them because of others behavior."

\subsubsection{Moral thinking}

Moral thinking is one of the moral decision-making subcategories that include themes of effort in learning and moral education. Meditating and pondering on ethical issues and values clear the path of "what should be," and this will be realized for learning in light of efforts. Participant no. 5 said, "Teach your students to think right. If you and I act right, they look and follow us. The issues should be highlighted so that the students can think on them and conclude."

\subsubsection{Moral reasoning}

Moral reasoning is a kind of moral thinking to achieve moral judgments of behaviors and disproving some other behaviors and includes logical thinking and reasoning abilities. Participant no. 10 stated, "My friend trusted me that she had told out here wrongs. On the one hand, we are supporting the patient what to do? Here, I faced many challenges. I checked the mistake occurred to see if it is dealing with sick life or not? Can I help them or not? I finally take my decision."

\subsubsection{Moral courage}

Moral courage means to resist for what is right and requires a constant commitment in the field of ethics despite the potential risks that threaten the nurse position. In this case, Participant no. 5 said, "It was very difficult when I saw the patient got hematuria only because Mr. X Lack of skills in probing, the patient was suffering. I am a nurse, but he was a resident, but I did not tolerate and called his attend and told him to stay until the patient's condition get stable. Although he competed with me when he was in our part created problems for me, but I was happy that I did that."

\subsection{Moral care}

Another theme that emerged is moral care. Commitment to ethics in nursing care is defined as the core of nursing values and reflects respect level for the patient personality during care, the degree of concern for the patient security, the holistic point of view to him, and also taking into account the principle of justice in the care issue. Thus, moral care is classified into the subcategories of dignified care, safe care, fair care, and holistic care.

\subsubsection{Dignified care}

The first subcategory of these themes is dignified care, which consists of confidentiality, patient privacy, patients' rights, cooperation, courtesy and respect, mutual trust, being honest, effective communication, positive impact on patient involvement, and the patients' consent. All the people are valued and respected, which means keeping their dignity and position that is a moral ideal. Participant no. 9 stated that, "A patient in the first place expect a good relationship, then expect the nurse to respect them so that make them feel valued. In the mind of the patient, this means that the nurse is coming here for me; it's important that patients feel valued and confident."

\subsubsection{Safe care}

The next subcategory is safe care, which includes creativity in care, improving the self-care in patients, appropriate service and expedite servicing, punctuality, attention to accuracy, valuing human life, trying to improve individual knowledge, commitment to raise the professional skills of others and responsibility. Participant no. 8 said, "There are nurses who support the students and help them to learn how to care for patients to not be injured."

\subsubsection{Fair care}

Fair care is another subcategory under moral care. Professional fairness and equal distribution of resources are components of fair treatment. Criteria for nursing care and practice includes patient's needs to receive care and priorities. Participant no. 9 said, "We all have to consider the regulations in our work. For example, my colleague tells me Mr. X is his friend, so let him go earlier to the ambulance corps. We should not act like this because of my colleague relationship with Mr. X. I think we have to divide the resources (time, medical attention, and sections) according to the patients' needs priority rather than involving other criteria."

\subsubsection{Holistic care}

Holistic care is the last subcategory related to moral care. Its implications are having a holistic view, understanding the situation, and flexibility. Nurses should view a patient as a human being with all aspects of humanity and, with regard to all economic and spiritual condition, will take care of him or her. Participant no. 9 said, "The nurse must know the patient as a person who has different needs and know these needs, take steps to resolve them, and do whatever he or she can for the patient."

\section{Discussion}

In the present study, moral character, moral decision, and moral care have emerged as the major aspects of moral competency. A 2007 study by Erikson showed that moral competency must be both morality (personality traits) and 
moral practice, which requires ethical knowledge (26); this is consistent with the main themes of this study. With the help of moral character and ethical knowledge, one can make moral decisions and, accordingly, take moral care of the patient. A 2015 study by Kulju stated that moral personality and character counts as dimensions of moral competency (27), which are in line with the results of the present study. A 2005 study by Jormsri found three areas of moral perception, moral judgment, and moral behavior for moral competency that are not consistent with the dimensions of the present study. Although the subjects of classes resulting from Jormsri's study have similarities with themes of the current study, they differ in main classes (9). The first theme of moral competency derived from interviews is moral character, which includes altruism, search for meaning, pioneering, perfectionism, self-control, honesty, and forgiveness. Moral character of the current study is based on the theory of virtue ethics, noting moral characteristics (28-30). A 2010 study by Izumi showed that, in a review on patients' perception of acknowledged care quality, a nurse's personality characteristics guarantee providing good and appropriate care to patient (31). Participants of the current study counted philanthropy as an important behavioral feature of nurses, which creates a desirable feeling after caring for the patient. A 2014 study by Mahasneh stated that moral competence as a kind of humanitarian behavior and moral judgment. He believes that humanitarian behavior will not only lead to providing quality care to a patient but also lead to nurse satisfaction (21). A 2010 study by Martin also showed counting humanitarian conduct as moral qualities that facilitate access to higher levels of recognition, mental capabilities that can be self-recognition (18). Search for meaning is another personality trait referred to. Many 2010 and 2009 studies by Steger and Moody showed that, according to Frankel, search for meaning is a rooted force in man. He does not consider the main purpose of life as escaping pain and seeking pleasure, but considers it a search for meaning (32, 33), which is consistent with the findings of the present study.

Be pioneering in the care and adoption of positive changes are other concepts of moral character in the present study. This characteristic creates a sense of peace and inner satisfaction in nurses so that, a study by Gulea, also pioneering in the care of patients with brain problems, led to results that were similar to that of the current study (34). Honesty is another part of moral characteristics that, in this study, are consistent with the findings of the study by Jormsri and Kulju $(9,27)$. Forgiveness is another part of moral characteristic themes resulting from the current study. Strelan declared in the process of forgiveness that nurses, instead of seeking revenge or punishment and compensation for the suffering, kindly forget everything, and the wrongdoers do not remain in their minds for long time (35). A 2014 study by Waserman also showed that the characteristic of forgiveness as moral imperative for nurses (3). In a number of studies, enabling themselves and others is considered as a great moral characteristic in humans. A 2006 study by Armstrong stated that one characteristic of moral thinking is consulting with experts in complex ethical situations (29); in the present study, participants also stated that, in some ethical situations, decision-making is difficult. When they are not able to solve the problem, they benefit from consultation with others. A 2012 study by Molewijk, also entitled moral consulting, improving ethical and professional qualifications and care quality, suggests that moral thinking increases the staffs' moral competency and improves the quality of care, increases transparency of the decision-making process, increases rational behavior, and improves the quality of management (38). A 2015 study by Kulju also pointed out moral courage as a component of moral competency (27). A 2010 study by Lachman called the person's capacity to overcome fear and stand for its main values as moral courage calls (39). Remarks by participants in the present study also support the same thing. Moral care is counted as the third main theme of moral competency. According to quad ethical principles of autonomy, beneficence, nonmal-efficiencies and justice, moral care is a care in which the four principles are considered (40). Pursuant to the obtained definitions, participants in the present study states that a kind of care is ethical in which the four principles, including dignified, safe, fair, and holistic care, would be given to the patient. In this regard, Jonston, as quoted from the World Health Organization in bio-ethical discourse, referred to quality care as the moral care and considers improving organizational ethics, noting that an increase of nurses' moral capacity is effective to achieve that (20). A 2010 study by Aguero defined quality care as providing timely health care to patients by professionally qualified personnel in accordance with safety and respect for ethical principles to meet the health needs and expectations of individuals (41), but do not count it directly as part of moral competency. Dignified care is the first subcategory of moral care, which has been formed of the contents of confidentiality, patient privacy, patient rights, courtesy and respect, mutual trust, effective communication, positive impact on patients, and patient satisfaction. Regarding that all human beings possess the sublime human dignity and should be respected in any condition, but patients and healthy people who have a requirement in relation with their health deserve special attention and respect (42). A 2005 study by Jormsri considered respect for patient as the moral qualities of nurses and that believes nurses who respect patients are more trusted, and patients experience more relaxation with them; in this way, their participation is provoked to provide more quality care (9). Some 2008, 2013, and 2014 studies by Gallagher, Edlund, and Borhani showed that respect for the patient's dignity is as a central value in nursing codes. Nurses learn to deal with human 
rights, including cultural rights, life and choice rights with respect, and dignified care is among the first tasks that prove behavior is moral and necessary for health care $(17,19,42)$. A 2008 study by Van about keeping the patient's dignity also stated that the patient may be willing to do prayer, meditation, and read the Bible during his or her stay in a hospital. This is a part of the nurse's professional responsibility to respect the patient and his or her beliefs as much as possible and provide facilities for the patient's performance of religious practices (43). All items listed are in line with the results of the current study. One of the subcategories resulting from the theme of moral care is safe care; its components include creativity in caring, value for human life, attempt to improve individual knowledge, commitment to enhancing professional skills, and responsibility. Axley and Sarvimaki, in their studies about Huber Max philosophical nursing theory, claimed that considered nursing care as a kind of ethical, practical, social, communicative, and creative activity and believed that nursing is basically a moral art where the nurse who is a creative artist provides the patient with creative and moral care and thus present care for patients that bring maximum immunity $(12,44)$. A 2014 study by Jonston suggested that making moral and effective relationships with patients can make the care given the patient much safer. He also says that the increased focus on scientific and technological aspects and efforts to promote nurses' academic level are other effective factors of safe care. There are standards in working environments conducive to learning, strict moral accountability, and the implementation of a safe and competent care (20). Green does not consider attempts to raise individual knowledge separated from moral and required for decisions about patients (22). Some 2008, 2010, and 2008 studies by Axley, Castro, and Galagr claimed that knowledge, skills, and ability to do the job are important in moral competency and results in providing better care and keeping patients safe $(12,19,45)$. Axley describes moral competency as meta-competency - an integral part of knowledge, skills, and competence - as an essential component of accountability and independence for development (12). Accountability is a component of safe care, which is referred to in the present study. A 2008 study by Martin also showed that accountability is a necessary factor for safe care (18). Cava and Jormsri refer to the nurse's moral competency but do not directly talk about the relationship between that and safe care $(9,46)$.

Another subcategory of moral care is holistic care. The nurse takes care of an individual, which forms a complex unit being, a being that has a permanent relationship both with themselves and the world. Participants in the current study emphasized that, considering all aspects and taking care of all aspects of the patient's being, are among the moral characteristics of a nurse. A 2014 study by Guevara also claimed that, in nursing care, it is supposed that a human is formed from a comprehensive aspects of experience, meanings, feelings, and emotions structure, intuition, and reasoning - and all of these aspects need attention and care (47). Nurses do not look at patients as multiple organs and systems, but they have an overall vision regarding the individual and accepting him or her as a unit that has ethical sense. In fact, holistic care is care of people as a whole, including the mind, body, and soul (48). Alligood also quoted from Martha Rogers who claimed that nursing is a holistic science and takes a holistic look at the man (49). Findings of the current study also support this point. From all the results of the present study, it can be inferred that, for good and moral care, agents are needed, which themselves have moral characteristics that are classified into several areas that could be indicative of a moral care model. A nurse by the help of moral characteristic acquired through inheritance and culture, religion, environment, etc. makes moral decisions and with these decisions designs his or her own moral care plan in which the patient enjoys security and justice; the patient's dignity is preserved and all aspects of his or her being are taken care.

\section{Conclusions}

The findings of this study showed that nurses' moral competency has broad dimensions such as moral character, moral decision making, and moral care. It represents a wide range of competency, which means it is a metacompetency. The importance of this finding applied in education and nursing ethics classes helps one to gain these competencies. In addition, by strengthening these dimensions, nurses can achieve better care for patients, and patient satisfaction is provided. Nursing managers can consider them in recruiting nurses. It is recommended that an additional study, designing "moral competency scale," be made for nurses according to Iranian culture. It could be a good suggestion for future research on this topic.

\section{Acknowledgments:}

This study is a result of a research thesis presented in Kerman University of Medical Sciences and the financial support of its research deputy. We would hereby like to thank the support of the university research deputy. We also appreciate the devoted collaboration of nurses who participated in the study.

\section{Conflict of Interest:}

There is no conflict of interest to be declared. 


\section{Authors' contributions:}

All authors contributed to this project and article equally. All authors read and approved the final manuscript.

\section{References:}

1) Kavathatzopoulos I, Rigas G. A measurement model for ethical competence in business. Journal of Business Ethics Education. 2006; 3: 55-74. doi: 10.5840/jbee200634.

2) Kavathatzopoulos I. The Use of Information and Communication Technology in the Training for Ethical Competence in Business. Journal of Business Ethics. 2003; 48(1): 43-51. doi: 10.1023/B:BUSI.0000004366.08853.72.

3) Wasserman JA, Stevenson SL, Claxton C, Krug EF. Moral Reasoning among HEC Members: An Empirical Evaluation of the Relationship of Theory and Practice in Clinical Ethics Consultation. J Clin Ethics. 2015; 26(2): 108-17. PMID: 26132057.

4) Nor Hafizah N, Zaihairul I, Geshina Ayu M. Moral competencies among Malaysian youth. Health And The Enviroment Journal. 2012; 3(3): 1.

5) Holloway I, Wheeler S. Qualitative research in nursing and healthcare. John Wiley \& Sons. 2013.

6) Varghese BP, Raj S. Do Metaphysical Beliefs Manipulate Moral Competency? A Study in the Context of Cultural Diversities, Involving Global Population. International Journal of Scientific Research in Knowledge. 2014; 2(7):328-39. Available from: http://www.ijsrpub.com/ijsrk. doi: 10.12983/ijsrk;2014:0328-0339.

7) Borhani F, Jalali T, Abbaszadeh A, Haghdoost A. Nurses' perception of ethical climate and organizational commitment. Nursing ethics. 2014; 21(3): 278-88. doi: 10.1177/0969733013493215. PMID: 24019306.

8) Zhang Z, Luk W, Arthur D, Wong T. Nursing competencies: personal characteristics contributing to effective nursing performance. J Adv Nurs. 2001; 33(4): 467-74. doi: 10.1046/j.1365-2648.2001.01688.x. PMID: 11251734.

9) Jormsri P, Kunaviktikul W, Ketefian S, Chaowalit A. Moral competence in nursing practice. Nurs Ethics. 2005; 12(6): 582-94. doi: 10.1191/0969733005ne828oa. PMID: 16312087.

10) Paganini MC, Egry EY. The ethical component of professional competence in nursing: an analysis. Nurs Ethics. 2011; 18(4): 571-82. doi: 10.1177/0969733011408041. PMID: 21646322.

11) Larcher V, Slowther AM, Watson AR. Core competencies for clinical ethics committees. Clin Med. 2010; 10(1): 30-3. PMID: 20408302.

12) Axley L. Competency: a concept analysis. Nurs Forum. 2008; 43(4): 214-22. doi: 10.1111/j.17446198.2008.00115.x. PMID: 19076465.

13) Kalantari M, Kamali M, Joolaee S, Rassafiani M, Shafarodi N. Perception of professional ethics by Iranian occupational therapists working with children. J Med Ethics Hist Med. 2015; 8: 8. PMID: 27354897, PMCID: PMC4922314.

14) Borhani F, Abbaszadeh A, Nakhaee N, Roshanzadeh M. The relationship between moral distress, professional stress, and intent to stay in the nursing profession. J Med Ethics Hist Med. 2014; 7: 3. PMID: 25512824, PMCID: PMC4263391.

15) Borhani F, Abbaszadeh A, Rabori RM. Facilitators and Threats to the Patient Dignity in Hospitalized Patients with Heart Diseases: A Qualitative Study. Int J Community Based Nurs Midwifery. 2016; 4(1): 3646. PMID: 26793729, PMCID: PMC470981016.

16) Borhani F, Hoseini H, Zadeh AA, Abbasi M, Fazljoo E. Nurses' perceptions of ethical climate governing the teaching hospital affiliated with the University of Medical Sciences Shahid Sadughi Yazd. Medical Ethics. $2015 ; 8(29): 41-65$.

17) Borhani F, Hosseini SH, Abbaszadeh A. Commitment to care: a qualitative study of intensive care nurses' perspectives of endoflife care in an Islamic context. Int Nurs Rev. 2014; 61(1): 140-7. doi:10.1111/inr.12079. PMID: 24382147.

18) Martin DE, Austin B. Validation of the moral competency inventory measurement instrument: Content, construct, convergent and discriminant approaches. Management Research Review. 2010; 33(5): 437-51. Available from: http://ssrn.com/abstract=1739053.

19) Gallagher A, Li S, Wainwright P, Jones IR, Lee D. Dignity in the care of older people-a review of the theoretical and empirical literature. BMC Nurs. 2008; 7: 11. doi: 10.1186/1472-6955-7-11. PMID: 18620561, PMCID: PMC2483981.

20) Johnstone MJ. Poor working conditions and the capacity of nurses to provide moral care. Contemp Nurse. 2002; 12(1): 7-15. PMID: 12013521. 
21) Mahasneh AM. The level of moral competence among sample of Hashemite university students. Canadian Social Science. 2014; 10(1): 159-64. doi: 10.3968/j.css.1923669720141001.4096.

22) Greene J, Haidt J. How (and where) does moral judgment work? Trends Cogn Sci. 2002; 6(12): 517-23. PMID: 12475712.

23) Vaismoradi M, Turunen H, Bondas T. Content analysis and thematic analysis: Implications for conducting a qualitative descriptive study. Nursing \& health sciences. 2013; 15(3): 398-405. doi: 10.1111/j.13652648.2007.04569.x.

24) Denzin NK, Lincoln YS, Giardina MD. Disciplining qualitative research 1. International Journal of Qualitative Studies in Education. 2006; 19(6): 769-82. doi: 10.1080/09518390600975990.

25) Polit D, Beck C. Essentials of nursing research. Ethics. 8th ed. 2014.

26) Eriksson S, Helgesson G, Hoglund AT. Being, doing, and knowing: Developing ethical competence in health care. Journal of Academic Ethics. 2007; 5(2): 207-16. doi: 10.1007/s10805-007-9029-5.

27) Kulju K, Stolt M, Suhonen R, Leino-Kilpi H. Ethical competence: A concept analysis. Nurs Ethics. 2016; 23(4): 401-12. doi: 10.1177/0969733014567025. PMID: 25670176.

28) Tabatabaee S. Medical and clinical practice moral virtues. Medical Ethics. 2013; 7(26): 31-45.

29) Armstrong AE. Towards a strong virtue ethics for nursing practice. Nurs Philos. 2006; 7(3): 110-24. doi: 10.1111/j.1466-769X.2006.00268.x. PMID: 16774598.

30) Gregory J. Lectures on the Duties and Qualifications of a Physician. Springer. 1998; 57: 161-245. doi: 10.1007/978-0-585-32315-2-8.

31) Izumi S, Baggs JG, Knafl KA. Quality nursing care for hospitalized patients with advanced illness: Concept development. Res Nurs Health. 2010; 33(4): 299-315. doi: 10.1002/nur.20391. PMID: 20572095, PMCID: PMC3241609.

32) Steger MF, Oishi S, Kesebir S. Is a life without meaning satisfying? The moderating role of the search for meaning in satisfaction with life judgments. The Journal of Positive Psychology. 2011; 6(3): 173-80. doi: 10.1080/17439760.2011.569171.

33) Moody HR. The Search for Meaning in Later Life. The Gerontologist. 2009; 49(6): 856-9. doi: 10.1093/geront/gnp146.

34) Gulea C, Cassidy M. A systematic review update on "Volunteering in the care of people with severe mental illness: a systematic review. BMC Psychiatry. 2012; 12: 226. doi: 10.1186/1471-244X-12-226.

35) Strelan P, Covic T. A review of forgiveness process models and a coping framework to guide future research. Journal of Social and Clinical Psychology. 2006; 25(10): 1059-85. doi: 10.1521/jscp.2006.25.10.1059.

36) Ferrell B, Otis-Green S, Baird RP, Garcia A. Nurses' Responses to Requests for Forgiveness at the End of Life. J Pain Symptom Manage. 2014; 47(3): 631-41. doi: 10.1016/j.jpainsymman.2013.05.009.

37) Park N, Peterson C. Moral competence and character strengths among adolescents: The development and validation of the Values in Action Inventory of Strengths for Youth. J Adolesc. 2006; 29(6): 891-909. doi: 10.1016/j.adolescence.2006.04.011. PMID: 16766025.

38) Weidema FC, Molewijk AC, Widdershoven GA, Abma TA. Enacting ethics: Bottom-up involvement in implementing moral case deliberation. Health Care Anal. 2012; 20(1): 1-19. doi: 10.1007/s10728-0100165-5.

39) Lachman VD. Clinical ethics committees: organizational support for ethical practice. Medsurg Nurs. 2010; 19(6): 351-3. PMID: 21337994.

40) Adela CM, Popa C. Bioethical principles available in therapeutic communication through SMS. Revista Romana de Bioetica. 2014; 12(1): 85-97.

41) Aguirre-Gas HG, Zavala-Villavicencio JA, Torres FH, Fajardo-Dolci G. Quality of medical care and surgical patient safety: medical error, malpractice and professional liability. Cir Cir. 2010; 78(5): 454-9. PMID: 21219820.

42) Edlund M, Lindwall L, von Post I, Lindström UÅ. Concept determination of human dignity. Nurs Ethics. 2013; 20(8): 851-60. doi: 10.1177/0969733013487193. PMID: 23812559.

43) Van Leeuwen R, Tiesinga LJ, Middel B, Post D, Jochemsen H. The effectiveness of an educational programme for nursing students on developing competence in the provision of spiritual care. J Clin Nurs. 2008; 17(20): 2768-81. doi: 10.1111/j.1365-2702.2008.02366.x. PMID: 18808646.

44) Sarvimäki A. Nursing care as a moral, practical, communicative and creative activity. J Adv Nurs. 1988; 13(4): 462-7. doi: 10.1111/j.1365-2648.1988.tb02850.x. PMID: 3221017. 
45) Castro ML, Martins N. The relationship between organisational climate and employee satisfaction in a South African information and technology organization. SA Journal of Industrial Psychology. 2010; 36(1): 1-9. doi: 10.4102/sajip.v36i1.800.

46) Cava A, Mayer D. Integrative social contract theory and urban prosperity initiatives. Journal of Business Ethics. 2007; 72(3): 263-78. doi: 10.1007/s10551-006-9169-3.

47) Guevara B, Evies A, Rengifo J, Salas B, Manrique D, Palacio C. Nursing care: an integrating vision in times of crisis. Enfermería Global. 2014; 33: 328-35.

48) Dossey BM, Certificate C-DINC, Keegan L, Co-Director International Nurse Coach A. Holistic nursing. Jones \& Bartlett Publishers. 2012.

49) Alligood MR. Nursing theorists and their work. Elsevier Health Sciences; 6th edit. 2013. 